\title{
The Effect of Acute Protein Consumption on Glycaemic Control and Insulin Response in Prediabetic Asian Chinese and Caucasian Adults ${ }^{\dagger}$
}

\author{
Wilson Yip ${ }^{1, *}$, Ivana Sequeira ${ }^{1}$ and Sally Poppitt ${ }^{1,2}$ \\ 1 Human Nutrition Unit, School of Biological Sciences, University of Auckland, \\ Auckland 1010, New Zealand; i.sequeira@auckland.ac.nz (I.S.); s.poppitt@auckland.ac.nz (S.P.) \\ 2 Department of Medicine, University of Auckland, Auckland 1010, New Zealand \\ * Correspondence: w.yip@auckland.ac.nz; Tel.: +64-21-120-3238 \\ + Presented at the 2019 Annual Meeting of the Nutrition Society of New Zealand, Napier, New Zealand, \\ 28-29 November 2019.
}

Published: 16 December 2019

Keywords: prediabetes; pancreas fat; protein; insulin

Dietary protein consumption has been shown to decrease postprandial hyperglycaemia. Whey protein in particular stimulates insulin secretion. The aim of this study was to assess the effect of acute whey protein consumption on established and novel markers of type 2 diabetes (T2D) risk; and to investigate whether greater ectopic lipid deposition in the pancreas, key site for insulin secretion, may alter the response to dietary whey protein intervention.

This was a randomised, 3 treatment cross-over study consisting of 24 female Asian Chinese ( $n=$ $12)$ and Caucasian $(n=12)$, aged $18-65$ years and with BMI $23-40 \mathrm{~kg} / \mathrm{m}^{2}$. At screening, all participants were prediabetic (raised fasting plasma glucose (FPG), 5.6-6.9 mmol/L) and were confirmed with $>4 \%$ or $<4 \%$ pancreas fat assessed by magnetic resonance imaging (MRI). Each participant attended the Human Nutrition Unit (HNU), University of Auckland for 3 study visits over 3 weeks, with a minimum 7 day wash-out period. At each visit, anthropometry was measured and a fasted baseline ( $\mathrm{T}=0 \mathrm{~min}$ ) blood sample was collected. Following consumption of the test breakfast drink; either water, low-dose protein or high-dose protein, blood samples were collected over a $4 \mathrm{~h}$ period $(\mathrm{T}=15$, $30,60,90,120,180$ and $240 \mathrm{~min}$ ).

There was no difference in glycaemic control between all 3 groups. Whey protein consumption significantly increased insulin secretion $(p<0.05)$ after both low and high protein drinks, with high protein drink demonstrating a greater effect $(p<0.05)$. Peak plasma insulin was higher in women with low pancreas fat in both protein groups, and was statistically significant $(p<0.05)$ following consumption of the high protein drink. The difference in plasma insulin concentration was significantly $(p<0.05)$ higher 15 min after the high protein drink in individuals with low pancreas fat.

The high protein drink significantly increased circulating insulin concentrations, whilst high pancreas fat decreased insulin probably due to pancreatic b-cell dysfunction and decreased insulin secretion.

Funding: The New Zealand National Science Challenge High Value Nutrition Program, Ministry for Business, Innovation and Employment (MBIE, grant no. 3710040).

(C) 2019 by the authors. Licensee MDPI, Basel, Switzerland. This article is an open access article distributed under the terms and conditions of the Creative Commons Attribution (CC BY) license (http://creativecommons.org/licenses/by/4.0/). 